\title{
GÉNERO E REPRESENTAÇÕES SOCIAIS: DUPLO-PADRÃO SEXUAL EM FUNÇÃO DA RELIGIÃO E DA POSIÇÃO POLÍTICA
}

\author{
Marta Pereira Alves ${ }^{1}$ \\ Ligia Amâncio ${ }^{2}$ \\ Valentim Rodrigues Alferes ${ }^{3}$
}

Resumo: O estudo de natureza não experimental apresentado pretendeu identificar e caracterizar os padrões sexuais pré-matrimoniais aos níveis individual e social e analisá-los em função do sexo, religião e posição política numa amostra de 308 estudantes do ensino superior. Os resultados apontaram para a adesão ao duplo-padrão sexual ao nível individual, mas para uma maior consensualidade na sua forma social, isto é, na percepção dessa duplicidade moral nos julgamentos e nas avaliações dos comportamentos sexuais pela sociedade em geral. Da análise da influência da opção religiosa e da posição política sobre as representações sociais da sexualidade pré-matrimonial, observou-se que os factores religiosidade e conservadorismo político estão negativamente associados à permissividade das atitudes sexuais, apesar da tendência comum dos diferentes grupos religiosos e políticos para a adesão ao duplo-padrão sexual, nas suas duas formas, individual e social. As implicações dos resultados são discutidas no âmbito da teoria das representações sociais e do género.

Palavras-chave: Género, representações sociais, duplo-padrão sexual, religião, posição política, ideologia.

Gender and social representations: dual sexual pattern as a function of religion and political opinion (Abstract): The non-experimental study presented sought to identify and characterize pre-matrimonial sexual standards at an individual and social level and analyze these norms as a function of sex, religion and political opinion in a sample of 308 graduate students. The results point to the adherence to the double standard at an individual level in a tenuous form, gathering more consensus in its social form, i.e. in the perception of moral duplicity

\footnotetext{
${ }^{1}$ Departamento de Psicologia e Educação da Universidade da Beira Interior. Email: mpalves@ubi.pt

2 ISCTE - Instituto Universitário de Lisboa.

${ }^{3}$ Faculdade de Psicologia e Ciências da Educação da Universidade de Coimbra.

PSICOLOGIA, Vol. XXII (2), 2008, Edições Colibri, Lisboa, pp. 139-160.
} 
within the judgments and evaluations of sexual behavior by society in general. The analysis of the influence of religion and political opinion on social representations of pre-matrimonial sexuality highlighted the fact that, despite religious factors and conservative political opinions are negatively associated to experience and permissiveness of sexual attitudes, there is a common tendency within religious and political groups towards the adherence to the sexual double-standard both at an individual and social form. The implications of results are discussed within the framework of social representations theory and gender.

Keywords: Gender, social representations, sexual double standard, religion, political opinion, ideology.

\section{Introdução}

\subsection{Género e sexualidade na teoria das representações sociais}

O género, enquanto representação social, constitui uma construção social do sexo que, como Amâncio (2001) refere, «dá sentido à nossa identidade sexual e às dos outros, aos objectos e aos contextos sexuados» (p. 16), incluindo as próprias situações experimentais. De acordo com a autora, a abordagem do género, ao restringir-se aos níveis intrapsíquico e interindividual, não permite a compreensão dos seus significados, nem da forma como sinaliza e organiza os comportamentos e as relações sociais com os outros e com o mundo. A integração do nível ideológico (Doise, 1984) nos estudos de género é fundamental face à permeabilidade dos significados dos traços associados ao sexo masculino e ao sexo feminino, às particularidades dos contextos social e cultural e a um sistema de valores mais amplo.

No contexto da teoria das representações sociais, os processos de objectivação e de ancoragem (Moscovici, 1984) envolvidos na formação das representações do género, são salientados por Amâncio (2001). Os processos de objectivação, através dos quais um esquema conceptual se materializa e se torna numa realidade pensada como natural, remetem para as crenças associadas às categorias de sexo, nomeadamente para os estereótipos sexuais e para as atitudes perante os papéis sexuais (Deaux \& Kite, 1989), que identificam o homem com a imagem do indivíduo racional, independente, afirmativo e civilizado, sendo a representação da mulher essencialmente de cariz sexual. Em relação à ancoragem, que corresponde à assimilação dos objectos a esquemas cognitivos por aproximação a categorias de objectos pré-existentes, os traços do estereótipo masculino confundem-se com os do indivíduo adulto, o que não acontece com os traços do estereótipo feminino (Amâncio, 1998a, 1998b). Segundo a autora, este 
resultado, que exprime uma assimetria simbólica, traduz uma representação social hegemónica comum à maioria dos países desenvolvidos, que se caracteriza pela universalidade dos significados masculinos como referência simbólica para ambos os sexos e pela especificidade dos femininos remetida para o contexto familiar e privado.

As representações sociais associadas ao género são, no nosso estudo, estudadas no contexto particular da sexualidade pré-conjugal. Daí, os significados implicados nos estereótipos, nas crenças e nas opiniões associadas ao sexo remeterem para um fundo ideológico comum e as construções sociais associadas ao género prescreverem determinantemente as práticas e as representações da sexualidade (Paicheler, 1995). A definição do nosso problema geral de estudo baseou-se na conceptualização teórica de Jodelet (1997, p. 53), que define uma representação social como «uma forma de conhecimento, socialmente elaborada e partilhada, com um objectivo prático e contribuindo para a construção de uma realidade comum a um conjunto social». Seguindo os critérios apontados por Vala (2000) que autorizam que uma representação seja social - o critério quantitativo, o critério genético e a funcionalidade -, e aplicando-os à problemática da sexualidade pré-conjugal, esta ganha relevância como fenómeno de representação social. Como os resultados de estudos portugueses (e.g., Alferes, 1997) e estrangeiros (e.g., Apostolidis, 1995) revelam, as representações da sexualidade juvenil são partilhadas pelos jovens (critério quantitativo), são produto das interacções sociais e da comunicação no interior desse grupo (critério genético) e permitem a orientação da comunicação e dos seus comportamentos (funcionalidade). Pode ainda conjecturar-se que a sexualidade pré-matrimonial, especialmente dos jovens, surgiu como fenómeno de representação social, com relevância cultural e social no mundo ocidental, a partir dos nos 60 , já que, até então, era considerado um fenómeno social marginal e fortemente reprimido. Embora a sexualidade se reporte à esfera privada dos indivíduos, Jovchelovitch (1994, p. 71) indica que «é através da acção de sujeitos sociais que agem no espaço que é comum a todos, que a esfera pública aparece como o lugar onde uma comunidade pode desenvolver e sustentar saberes sobre si própria, ou seja, representações sociais».

\subsection{Nivel ideológico das representações sociais}

Os processos de elaboração e de circulação das representações sociais são conceptualizados por Spink (1994) numa perspectiva temporal. A autora refere três tempos distintos que definem o conteúdo das representações sociais: um tempo mais imediato que remete para a funcionalidade das representações sociais nas interacções e comunicação; um tempo intermédio que abarca o processo de socialização e a pertença a determinados grupos sociais; 
e um tempo longo das memórias colectivas, que ancora em produções culturais e sociais mais remotas, que forma o imaginário social e que vai ficando cristalizado ao longo do tempo em imagens, mitos e rituais e na linguagem. Em particular, a análise deste tempo de contextualização histórica e de génese social das representações sociais do duplo-padrão sexual, que forma os conteúdos mais estáveis das representações, remete-nos para o modo como estas se estruturam nas diferenças ideológicas associadas ao género.

Segundo Sá (1998), a perspectiva psicossociológica das representações sociais privilegia a influência que o sistema social tem sobre o sistema cognitivo, ou seja, sobre a formação e o conteúdo de uma representação. Como Doise (1990) sublinha, a elaboração das representações sociais depende das suas ligações com os sistemas ideológicos. Da mesma forma, Palmonari e Doise (1986) atribuem à ideologia a estabilidade e a homogeneidade, que as representações sociais não possuiriam pelo seu carácter mais difuso e mutável. As representações sociais analisadas a um nível ideológico incluem uma dimensão mais geral das relações sociais, que envolve «crenças ideológicas universais», das quais resultam determinadas representações e comportamentos individuais (Doise, 1984).

\subsection{Duplo-padrão sexual e ideologia: religião e posição política}

Segundo Alferes (1987), o conceito de representação social permite a integração entre comportamentos e instituições, colocando a questão da sexualidade para além da dicotomia instinto/norma. DeLamater (1987) sublinha o papel, na regulação da sexualidade, das instituições sociais e normativas, em particular da religião, da família, da economia, da medicina e do sistema jurídico-legal. De modo semelhante, Giami (1999) refere-se a três níveis na análise das representações da sexualidade. A um nível social, que corresponderia ao nível ideológico, são estudados os discursos na sua particularidade social e histórica, nomeadamente o discurso médico, psicológico e educativo, o discurso jurídico, o discurso religioso, o discurso cultural e o discurso da imprensa. A um nível intermédio e mediador situam-se as relações entre os indivíduos, nas quais são negociados os discursos dominantes. Finalmente, as representações ao nível individual seriam, mais ou menos, directa e sistematicamente influenciadas pelos discursos públicos dominantes ou, mais ou menos, reinterpretadas pelos indivíduos, dependendo da força das orientações ideológicas numa determinada sociedade.

Especificamente, a religião deve ser considerada no estudo das representações sociais, na medida em que a filiação religiosa dos jovens é diferenciadora das construções acerca de si, dos outros e da realidade (Antunes, 1985). Em relação ao papel da religião na estruturação das representações da sexualidade pré-conjugal, alguns dos estudos portugueses (e.g., Alferes, 
1997; França, 1986, Pais, 1985; Vasconcelos, 1998) apontam para um efeito significativo da religiosidade dos jovens na permissividade comportamental e atitudinal: quanto menos religiosos se consideram, mais tolerantes e experientes são sexualmente, sendo essa diferença mais vincada quando as práticas sexuais se reportam a contextos relacionais emocionalmente não significativos, o que traduz a sua maior adesão ao modelo hedonista da sexualidade. Esta mesma relação foi encontrada noutros países (e.g., Sheeran, Spears, Abraham \& Abrams, 1996; Weinberg, Lottes \& Shaver, 2000). Os jovens católicos demonstram igualmente uma maior culpabilidade face à possibilidade de actividade sexual pré-conjugal (Miguel \& Vilar, 1986). Já no estudo de França (1986), com uma vasta amostra de jovens portugueses, com idades entre os 15 e os 24 anos, verificou-se que a sexualidade constituia a área da vida dos jovens em que o grau de filiação religiosa tinha o maior impacte na respectiva diferenciação atitudinal, comparativamente a outras áreas como a escola, a participação social, a política ou a escolha dos valores finais. O duplo-padrão moral que estrutura as atitudes parentais face à sexualidade dos rapazes e das raparigas também é determinado pela religiosidade dos pais: os pais ateus mostram-se mais permissivos em relação aos comportamentos amorosos das filhas que os católicos praticantes (Pais, 1985; Vilar, 2003).

Vários estudos encontraram uma relação entre as atitudes políticas e a vivência da sexualidade nos jovens, apesar do pouco interesse face à política manifestado, desde há várias décadas, pela maioria dos jovens europeus (e.g., Reis, 1986). Contudo, alguns autores encontram uma associação significativa entre essas variáveis, que é caracterizada pela maior permissividade dos jovens que se posicionam politicamente à esquerda (e.g., Alferes, 1997). Também os jovens que manifestam menos interesse face à política vivenciam mais sentimentos de culpa face à sexualidade (Miguel \& Vilar, 1986).

\section{Método}

\subsection{Objectivos e hipóteses}

A presente investigação procura responder à questão se o duplo-padrão sexual ${ }^{4}$ constitui uma representação socialmente partilhada entre os

\footnotetext{
${ }^{4}$ A definição de duplo-padrão sexual adoptada neste estudo é mais abrangente que a definição de duplo-padrão sexual condicional considerada originalmente por Reiss (1960, 1967). O conceito de duplo-padrão sexual foi primeiramente introduzido por Reiss (1960, 1967), cuja tipologia de padrões sexuais pré-matrimoniais incluía a abstinência, o duplo-padrão, clássico e condicional, e os padrões singulares "sexo com afecto" e "sexo sem afecto". O duplo-padrão sexual condicional admite a actividade sexual feminina antes do casamento, ainda que condicionada pelo contexto relacional em que ocorre, ou seja, as
} 
jovens universitários portugueses, enquanto modelo dominante da sexualidade pré-matrimonial desse grupo de estudantes inserido num contexto sócio-cultural específico e em que medida é influenciado pelo sexo, prática religiosa e posição política dos jovens.

O duplo-padrão sexual é definido como duplicidade no julgamento, nas atitudes e nas normas face a várias práticas sexuais pré-matrimoniais e que é traduzida por uma menor permissividade na avaliação dos comportamentos e atitudes sexuais das mulheres. Espera-se encontrar um duplo-padrão sexual ao nível indivídual na avaliação de um conjunto de atitudes e comportamentos sexuais. O estudo de Milhausen e Herold (2001) sugere que, apesar do progressivo declínio das diferenças na percepção individual (i.e., "eu avalio...») das atitudes e comportamentos de homens e mulheres na sexualidade pré-matrimonial, o duplo-padrão sexual persiste de modo mais expressivo quando a duplicidade moral nos julgamentos dos comportamentos sexuais é avaliada do ponto de vista da sociedade em geral (i.e., «eu acho que a sociedade avalia...»). Assim, esperamos encontrar o duplo-padrão sexual ao nível social. Na esfera especificamente ideológica, esperamos encontrar resultados concordantes com os obtidos em vários estudos nacionais (e.g., Alferes, 1997; Miguel \& Vilar, 1986; Pais, 1985; Vasconcelos, 1998), ou seja, uma associação entre a permissividade das atitudes sexuais e comportamentos sexuais e as variáveis religião e posição política. Em concreto, antecipamos uma maior permissividade comportamental e atitudinal associada a uma menor religiosidade e a um menor conservadorismo político.

\subsection{Participantes}

A presente investigação baseia-se nas respostas de uma amostra de 308 alunos do Ensino Superior Público Português (Universidade de Coimbra e Instituto Politécnico de Coimbra). A amostra é constituída por 140 rapazes $(45.5 \%)$ e 168 raparigas $(54.5 \%)$. A idade dos participantes situa-se, para ambos os sexos, entre os 18 e os 29 anos $^{5}$, sendo a média de idades de

relações sexuais pré-matrimoniais são permitidas às mulheres se vividas no quadro de uma relação estável e emocionalmente significativa. Na descrição do autor, o duplopadrão sexual condicional resulta de um declínio, na sociedade ocidental e a partir dos anos 60 e 70, da sua forma clássica, caracterizada pela permissividade exclusivamente masculina para o relacionamento sexual pré-matrimonial.

${ }^{5}$ Por se tratar de um estudo acerca dos padrões sexuais de jovens, não foram considerados neste estudo cinco questionários de participantes com idade igual ou superior a 30 anos. $\mathrm{O}$ intervalo de idades adoptado teve como referência o estudo recente de Milhausen e Herold (2001) com jovens, acerca do duplo-padrão sexual. Foram também excluídos cinco questionários de participantes casados cuja idade era superior a 29 anos, na medida em que se pretende estudar os padrões de sexualidade pré-matrimonial. Finalmente, exclui- 
21.31 e o desvio padrão de 2.71. A mediana é de 21 anos. Todos os inquiridos são solteiros. Dos estudantes da amostra, $83.1 \%$ afirmam ser católicos, $14.3 \%$ declaram não ter religião e os restantes $2.6 \%$ assumem outra religião. Dos $81.8 \%$ dos participantes que indicaram a sua posição política (os restantes não responderam à questão), $36.7 \%$ referem posicionar-se à direita $\mathrm{e}$ $45.1 \%$ à esquerda. As habilitações literárias do pai são iguais ou inferiores ao $4^{\circ}$ ano (i.e. até à escolaridade primária completa) para $40.3 \%$ dos inquiridos e superiores ao $12^{\circ}$ ano (i.e. com, no mínimo, a escolaridade secundária completa) para $43.0 \%$, situando-se os restantes $16.7 \%$ entre os dois níveis de escolaridade. Relativamente às habilitações literárias da mãe dos participantes, $38.7 \%$ são inferiores ao $4^{\circ}$ ano, $42.3 \%$ são superiores ao $12^{\circ}$ ano e $19.0 \%$ situam-se entre os dois níveis de escolaridade.

\subsection{Procedimento}

Depois de um pré-teste realizado com o objectivo de identificar itens de difícil compreensão, erros e redundâncias na estrutura e conteúdo dos itens, foram efectuadas algumas alterações na sua apresentação e correcções de vocabulário, ortografia e pontuação, tendo sido o inquérito administrado entre Março e Junho de 2004 em contexto de sala de aula. Foram realizadas 12 sessões, com um mínimo de 7 e um máximo de 93 participantes e com a duração média de 30-40 minutos. Estivemos presentes em todas as sessões, informando os participantes acerca do objectivo do estudo e instruções de preenchimento e respondendo a outras questões colocadas. Procurou-se, dentro do possível, uniformizar as condições de aplicação do inquérito nas várias sessões. Foram ainda garantidas as condições de anonimato e de preenchimento individual do inquérito e assegurada a credibilidade do estudo (nomeadamente, as ligações institucionais do investigador e a natureza científica da investigação).

\subsection{Questionário}

\subsubsection{Duplo-padrão sexual individual}

O grupo de questões utilizadas no estudo corresponde à tradução da versão original da Escala do Duplo-Padrão Sexual de Muehlenhard e Quackenbush (1998) ${ }^{6}$. De acordo com os autores da escala, o seu objectivo consiste em avaliar o grau de adesão ao duplo-padrão sexual, segundo o qual as mulheres são discriminadas negativamente relativamente ao envol-

ram-se quatro questionários incorrectamente preenchidos ou com «não-respostas» a itens cruciais.

${ }^{6}$ Os autores referem como valores do alfa de Cronbach, indicadores da consistência interna da escala, 0,73 para uma amostra de mulheres e 0,76 para uma amostra de homens. 
vimento sexual pré-matrimonial, à idade e ao contexto relacional considerados apropriados para esse envolvimento e ao número de parceiros sexuais permitido. A escala é composta por 26 itens avaliados numa escala de quatro pontos $(1=$ completamente em desacordo; $4=$ completamente de acordo). Seis desses itens incluem uma comparação entre homens e mulheres quanto aos seus comportamentos sexuais (e.g., « Acho que é mais reprovável para uma mulher ter vários parceiros sexuais do que para um homem»); os restantes vinte itens surgem agrupados em dez pares, sendo um desses itens dirigido aos comportamentos dos homens («Não vejo problema que um homem tenha relações sexuais com uma mulher que não ama») e o respectivo par relativo aos mesmos comportamentos, mas reportados às mulheres («Não vejo problema que uma mulher tenha relações sexuais com um homem que não ama»). A partir das 26 variáveis da escala, Muehlenhard e Quackenbush (1998) calcularam um indice global do duplo-padrão sexual, adoptado no presente estudo, que resultou do somatório das pontuações de 16 variáveis: os seis itens de comparação (após inversão dos itens negativos) e as diferenças entre as pontuações em cada um dos dez pares de itens que compõem o total dos vinte itens emparelhados, ou seja, à pontuação do item relativo aos comportamentos ou atitudes referidas à mulher é subtraída a pontuação do item acerca dos mesmos comportamentos ou atitudes, mas referenciado ao sexo masculino. ${ }^{7}$ Quanto à consistência interna da escala, calculado com base nas 16 variáveis derivadas, o valor do alfa de Cronbach encontrado foi de $0,68(N=308)$.

Com o propósito de envolver o próprio participante na situação, introduzimos quatro itens ( $1=$ nunca e $5=$ de certeza) que se referem às atitudes e comportamentos do respondente no que diz respeito à probabilidade de relacionamento (sério ou sem comprometimento) consoante a experiência sexual anterior do possível parceiro(a) (ausência ou elevado número de parceiros sexuais): «Envolver-se-ia sem qualquer «comprometimento» («encontro de uma noite») com um(a) homem/mulher que já tivesse tido um elevado número de parceiros sexuais/nunca tivesse tido relações sexuais?»; «Teria um relacionamento «sério» («namoro») com alguém que já tivesse tido um elevado número de parceiros sexuais/nunca tivesse tido relações sexuais?». Pretende-se avaliar as respostas em função do sexo, religião e

\footnotetext{
${ }^{7}$ Após a recodificação da escala (de 1-4 para 0-3)), este indicador varia entre o valor máximo de 48 (indicador da adesão ao duplo-padrão sexual, traduzido pela discriminação face aos comportamentos das mulheres relativamente aos dos homens) e valor mínimo de -30 (indicador de uma maior permissividade face aos comportamentos das mulheres em relação aos dos homens). O valor zero indica iguais padrões de avaliação dos comportamentos sexuais para homens e mulheres.
} 
posição política e, assim, identificar quais os contextos que geram maior discordância e maior consensualidade. ${ }^{8}$

\subsubsection{Duplo-padrão sexual social}

A partir do valor médio das respostas às três questões, que a seguir descrevemos, calculámos o indice global do duplo-padrão sexual social, que avalia em que medida os indivíduos consideram que a sociedade discrimina as mulheres, em relação aos homens, pelos mesmos comportamentos e atitudes sexuais. O primeiro item («As mulheres com muitos parceiros sexuais são avaliadas mais negativamente que os homens com o mesmo número de parceiros») procura avaliar, numa escala de cinco pontos $(1=$ completamente em desacordo; $5=$ completamente de acordo) o duplo-padrão sexual na sua perspectiva social quanto ao comportamento específico do número de parceiros sexuais. Uma segunda questão ( «Na sua opinião quem tem mais liberdade sexual nos dias-de-hoje?», em que $1=$ Os homens têm mais liberdade sexual do que as mulheres; $2=$ Os homens têm ligeiramente mais liberdade sexual do que as mulheres; $3=$ Os homens e as mulheres têm a mesma liberdade sexual; $4=$ As mulheres têm ligeiramente mais liberdade sexual do que os homens; 5 = As mulheres têm mais liberdade sexual do que os homens ${ }^{9}$ ), que, tal como o primeiro item, foi retirado do estudo de Milhausen e Herold (2001), pretende averiguar o grau de adesão ao duplo-padrão sexual social numa perspectiva geral, sem referência a comportamentos específicos, mas apenas ao conceito de liberdade sexual, que atravessa o discurso acerca da discriminação sexual, em particular desde o final dos anos 60. Finalmente, a partir de um terceiro item ( $\ll \mathrm{Na}$ sua opinião, a sociedade avalia de forma diferente os comportamentos sexuais das pessoas, consoante são homens ou mulheres»), construído com base na definição de duplo-padrão sexual social (Milhausen \& Herold, 2001), obteve-se o grau de adesão ao duplo-padrão sexual social $(1=$ adesão ao duplo-padrão sexual social com discriminação das mulheres; 2 = não adesão ao duplo-padrão sexual social; 3 = adesão ao duplo-padrão sexual social com discriminação dos homens $)^{10}$. Da análise da consistência interna das

\footnotetext{
${ }^{8}$ Através destes quatro itens, indirectamente, seria igualmente possível avaliar o duplopadrão sexual individual, mas apenas se considerarmos que a amostra em estudo é composta somente por heterossexuais, o que não podemos afirmar, na medida em que não recolhemos essa informação juntos dos participantes.

${ }^{9}$ Este item foi sujeito à inversão da respectiva escala para o cálculo do índice global do duplo-padrão sexual social.

10 Para calcular o índice global do duplo-padrão sexual social, as respostas ao grau de adesão ao duplo-padrão sexual social foram recodificadas (de 1 para 1, de 2 para 3 e de 3 para 5) e invertida a respectiva escala.
} 
três questões avaliadoras do duplo-padrão sexual social referidas, obteve-se um alfa de Cronbach de 0,74 $(N=308)$.

\subsubsection{Religião e posição política}

$\mathrm{O}$ indicador de religião que, tal como na investigação de Alferes (1997), foi calculado a partir das respostas aos itens acerca da posição religiosa e da prática religiosa, tem três categorias: 1 = católicos praticantes (posição católica e participação em cerimónias religiosas pelo menos aos domingos e festas religiosas); 2 = católicos não participantes (posição católica e não frequência ou frequência ocasional de cerimónias religiosas); $3=$ sem religião (posição sem religião) ${ }^{11}$. No respeitante às opções políticas dos inquiridos, estas foram recodificadas e classificadas em: $1=$ direita e $2=$ esquerda $^{12}$.

\section{Resultados}

Os resultados são apresentados em duas partes. A primeira inclui as análises que envolvem as variáveis caracterizadoras do duplo-padrão sexual individual e a seguinte integra as análises com as variáveis que definem o duplo-padrão sexual social. São analisadas as suas relações com a variável sexo e com duas variáveis de nível ideológico: a religião e a posição política. ${ }^{13}$

\subsection{Duplo-padrão sexual individual}

O estudo do duplo-padrão sexual numa perspectiva individual baseia-se na análise das seguintes variáveis: o índice global do duplo-padrão sexual individual de Muehlenhard e Quackenbush (1998) e a probabilidade de relacionamento (sério ou sem comprometimento) consoante a experiência sexual anterior do(a) possível parceiro(a) (ausência ou elevado número

11 Nas análises em que se utilizou este indicador, não foram considerados os oito participantes que assumiram ter outra religião, que não a religião católica, dada a sua percentagem ser muito reduzida $(2,6 \%)$.

12 Embora a percentagem de não resposta a essa questão (18.2\%) possa significar ausência de posição política, a não inclusão dessa alternativa de resposta no inquérito, leva-nos a não considerar nas análises os 56 participantes que não responderam.

$13 \mathrm{Na}$ amostra dos estudantes que participaram no estudo $(N=308)$, a diferença entre a média de idades dos dois sexos (1.52 anos) é estatisticamente significativa $[t(306)=$ $5.12, p<0,001]$. Por isso, quando, na análise da covariância, os testes para a idade (como covariável) forneceram valores estatisticamente significativos e a diferença nas observações o justificar, optou-se por remover esses efeitos, procedendo ao ajustamento das respectivas médias. 
de parceiros sexuais). O valor médio do índice global do duplo-padrão sexual individual para a totalidade da amostra foi de $8.54(D P=5.38)$, variando entre a pontuação mínima de -3 e a pontuação máxima de 29 . A mediana tem o valor de 8 e a moda o valor de 7. No grupo dos homens, a mediana e a moda têm o valor de 11; no caso das mulheres, a mediana é de 6.5 e a moda é de 7.

\subsubsection{Religião}

As variáveis caracterizadoras do duplo-padrão sexual individual foram objecto de uma análise da variância ${ }^{14} \mathrm{em}$ função da religião e do sexo dos jovens. No Quadro 1, indicam-se as respectivas médias e desvios-padrão em função da religião, para ambos os sexos e para a totalidade da amostra.

Relativamente ao índice global do duplo-padrão sexual individual, a análise univariada da variância não indica efeitos significativos para a religião $[F(2,294)=2.33, p>0,05]$, nem para a interacção entre religião e o sexo dos participantes $[F(2,294)=1.01, p>0,30]$. O efeito da variável sexo é estatisticamente significativo em relação ao mesmo indicador $[F(1$, $294)=20.70, p<0,001]$, traduzindo uma maior adesão dos homens a esse padrão. $\mathrm{Na}$ análise das variáveis que pretendem avaliar a probabilidade de envolvimento em relacionamentos ocasionais e sérios consoante a experiência sexual anterior (ausência ou elevado número de parceiros sexuais) do possível parceiro, o factor religião influencia com significância estatística as quatro variáveis, consideradas globalmente $[\tau=0,06, F(8,580)=2.02$, $p<0,05]$. Os testes univariados da variância ${ }^{15}$ indicam que existem diferenças significativas apenas no item relação sem comprometimento/elevado número de parceiros sexuais entre os três grupos religiosos $[F(2,294)=$ $\left.6.49, p<0,01, \eta^{2}=0,17\right]$. As comparações a posteriori (testes de Bonferroni) revelam diferenças significativas $(p<0,05)$ entre os católicos praticantes $(M=1.88 ; D P=0,86)$, por um lado, e os católicos não praticantes $(M=$ $2.32 ; D P=0,91)$ e os respondentes sem religião $(M=2.52 ; D P=1.11)$, por outro. O primeiro grupo revela menor grau de concordância face à possibilidade de um relacionamento com comprometimento com alguém muito experiente sexualmente.

$14 \mathrm{Na}$ análise univariada da covariância, no teste para a idade $[F(1,293)=2.16, p>0,10]$, o efeito não foi estatisticamente significativo, tendo-se procedido à análise da variância.

$15 \mathrm{O}$ teste multivariado $T$ de Hotelling para a idade forneceu um $\tau=0,010$ estatisticamente não significativo $[F(4,290)=0,73, p>0,50]$, o que dispensou o controlo estatístico da idade. 
Quadro 1. Duplo-padrão sexual individual em função da religião e do sexo: Médias e desvios-padrão.

\begin{tabular}{|c|c|c|c|c|c|c|c|c|}
\hline \multirow[b]{2}{*}{$\begin{array}{l}\text { Sexo } \\
\text { masculino }\end{array}$} & \multicolumn{2}{|c|}{$\begin{array}{c}\text { Católicos } \\
\text { praticantes }\end{array}$} & \multicolumn{2}{|c|}{$\begin{array}{c}\text { Católicos não } \\
\text { praticantes }\end{array}$} & \multicolumn{2}{|c|}{ Sem religião } & \multicolumn{2}{|c|}{ Total } \\
\hline & $M$ & $\overline{D P}$ & $M$ & $D P$ & $M$ & $D P$ & $M$ & $D P$ \\
\hline DPI & 9,12 & 5,56 & 11,33 & 5,59 & 9,20 & 5,54 & 10,61 & 5,63 \\
\hline $\mathrm{RSC} / \mathrm{E}$ & 2,28 & 0,89 & 2,66 & 0,97 & 2,90 & 1,33 & 2,62 & 1,03 \\
\hline $\mathrm{RS} / \mathrm{E}$ & 2,60 & 0,91 & 2,59 & 0,91 & 2,90 & 0,72 & 2,64 & 0,88 \\
\hline $\mathrm{RSC} / \mathrm{A}$ & 3,12 & 1,17 & 3,08 & 0,93 & 3,20 & 1,11 & 3,10 & 1,00 \\
\hline \multirow[t]{2}{*}{$\mathrm{RS} / \mathrm{A}$} & 3,92 & 0,86 & 3,86 & 0,82 & 4,00 & 0,86 & 3,89 & 0,83 \\
\hline & \multicolumn{2}{|c|}{$\mathrm{N}=25$} & \multicolumn{2}{|c|}{$\mathrm{N}=91$} & \multicolumn{2}{|c|}{$\mathrm{N}=20$} & \multicolumn{2}{|c|}{$\mathrm{N}=136$} \\
\hline $\begin{array}{l}\text { Sexo } \\
\text { feminino }\end{array}$ & $M$ & $D P$ & $M$ & $D P$ & $M$ & $D P$ & $M$ & $D P$ \\
\hline DPI & 6,70 & 4,65 & 7,00 & 4,73 & 6,29 & 4,14 & 6,81 & 4,60 \\
\hline $\mathrm{RSC} / \mathrm{E}$ & 1,66 & 0,76 & 1,99 & 0,72 & 2,21 & 0,78 & 1,93 & 0,76 \\
\hline $\mathrm{RS} / \mathrm{E}$ & 2,60 & 0,85 & 2,98 & 0,85 & 3,04 & 0,69 & 2,88 & 0,84 \\
\hline $\mathrm{RSC} / \mathrm{A}$ & 2,60 & 1,21 & 2,60 & 1,07 & 2,58 & 0,88 & 2,60 & 1,08 \\
\hline \multirow[t]{2}{*}{$\mathrm{RS} / \mathrm{A}$} & 3,83 & 0,82 & 3,76 & 0,85 & 3,63 & 1,17 & 3,76 & 0,89 \\
\hline & \multicolumn{2}{|c|}{$\mathrm{N}=47$} & \multicolumn{2}{|c|}{$N=93$} & \multicolumn{2}{|c|}{$\mathrm{N}=24$} & \multicolumn{2}{|c|}{$\mathrm{N}=164$} \\
\hline Total & $M$ & $D P$ & $M$ & $D P$ & $M$ & $D P$ & $M$ & $D P$ \\
\hline DPI & 7,54 & 5,08 & 9,14 & 5,60 & 7,61 & 4,99 & 8,53 & 5,43 \\
\hline $\mathrm{RSC} / \mathrm{E}$ & 1,88 & 0,86 & 2.32 & 0,91 & 2,52 & 1,11 & 2,24 & 0,95 \\
\hline $\mathrm{RS} / \mathrm{E}$ & 2,60 & 0,87 & 2,79 & 0,90 & 2,98 & 0,70 & 2,77 & 0,87 \\
\hline $\mathrm{RSC} / \mathrm{A}$ & 2,78 & 1,21 & 2,84 & 1,03 & 2,86 & 1,03 & 2,83 & 1,07 \\
\hline \multirow[t]{2}{*}{$\mathrm{RS} / \mathrm{A}$} & 3,86 & 0,83 & 3,81 & 0,84 & 3,80 & 0,105 & 3,82 & 0,87 \\
\hline & \multicolumn{2}{|c|}{$\mathrm{N}=72$} & \multicolumn{2}{|c|}{$\mathrm{N}=184$} & \multicolumn{2}{|c|}{$\mathrm{N}=44$} & \multicolumn{2}{|c|}{$\mathrm{N}=300$} \\
\hline
\end{tabular}

Nota . DPI = Índice global do duplo-padrão sexual individual; RSC/E = Relação sem comprometimento/ elevado número de parceiros sexuais; $\mathrm{RS} / \mathrm{E}=$ Relacionamento sério/elevado número de parceiros sexuais; RSC/A = Relação sem comprometimento/ausência de experiência sexual; RS/A = Relacionamento sério/ausência de experiência sexual. 


\subsubsection{Posição política}

No Quadro 2, referem-se as médias das variáveis do duplo-padrão sexual individual, em função da posição política, para ambos os sexos e para a totalidade da amostra.

Relativamente ao índice global do duplo-padrão sexual individual, da análise univariada da variância ${ }^{16}$ resultam efeitos não significativos, quer para a posição política $[F(1,248)=2.53, p>0,10]$, quer para a interacção da posição política com o sexo $[F(1,248)=0,44, p>0,50,]^{17}$. Tomando o conjunto das quatro variáveis que traduzem a probabilidade de relacionamento (sério ou sem comprometimento) consoante o número anterior de parceiros sexuais (ausência ou elevado número), o teste multivariado $T$ de Hotelling não atinge o limiar estatístico para a posição política $[\tau=0,03$, $F(4,245)=0,1.65, p>0,10]$, nem para a interacção do sexo com a posição política $[\tau=0,03, F(4,245)=2.06, p>0,08]$. Em relação aos resultados da análise da variância ${ }^{18}$ a que foram submetidas as respostas a estes quatro itens, os testes univariados são estatisticamente significativos para o factor posição política em relação ao item relação sem comprometimento/elevado número de parceiros sexuais $\left[F(1,248)=4.58, p<0,01, \eta^{2}=0,15\right]$, em que os inquiridos de esquerda $(M=2.33 ; D P=0,87)$, independentemente do sexo, mostram um maior grau de aceitação comparativamente aos jovens de direita $(M=2.08 ; D P=0,94)$. Este padrão de resultados verifica-se igualmente no item relação sem comprometimento/ausência de experiência sexual, embora o teste univariado não alcance o limite de significação estatística $\left[F(1,248)=2.62, p<0,05, \eta^{2}=0,07\right]$. $O$ efeito de interacção atinge $o$ nível de significância no item relacionamento sério/elevado número de parceiros sexuais $[F(1,248)=4.21, p<0,01]$, em que a atitude mais favorável pertence às mulheres cuja posição política se situa à esquerda e a menos favorável aos homens que se posicionam à esquerda. Já nos inquiridos de direita, não se observa nenhuma diferenciação entre os sexos.

16 Nas análises univariadas da covariância, não se obtiveram efeitos com significância estatística nos testes para a idade, em relação ao índice global do duplo-padrão sexual individual $[F(1,248)=0,53, p>0,40]$, não se tendo, por isso, procedido ao ajustamento das observações para a idade.

17 Tal como na análise anterior, o efeito da variável sexo é estatisticamente significativo em relação ao índice global do duplo-padrão sexual individual $[F(1,248)=29.61, p<0,001$, $\left.\eta^{2}=0,12\right]$.

$18 \mathrm{O}$ teste multivariado $T$ de Hotelling para a idade forneceu um $\tau=0,01$ não significativo $[F(4,244)=0,67, p>0,50]$, o que nos levou a proceder a uma análise factorial da variância e a não recorrer à análise da covariância. Os testes univariados das variáveis acerca da probabilidade de relacionamento (sério ou sem comprometimento) com alguém consoante o seu número anterior de parceiros sexuais (ausência ou elevado número) mantêm níveis de significância idênticos quer se considere, ou não, a idade como covariável. 
Quadro 2. Duplo-padrão sexual individual em função da posição política e do sexo: Médias e desvios-padrão.

\begin{tabular}{|c|c|c|c|c|c|c|}
\hline & \multicolumn{2}{|c|}{ Direita } & \multicolumn{2}{|c|}{ Esquerda } & \multicolumn{2}{|c|}{ Total } \\
\hline $\begin{array}{l}\text { Sexo } \\
\text { masculino }\end{array}$ & $M$ & $D P$ & $M$ & $D P$ & $M$ & $D P$ \\
\hline DPI & 10,88 & 6,03 & 10,27 & 5,95 & 10,54 & 5,97 \\
\hline $\mathrm{RSC} / \mathrm{E}$ & 2,53 & 0,97 & 2,59 & 0,97 & 2,57 & 0,97 \\
\hline $\mathrm{RS} / \mathrm{E}$ & 2,75 & 0,89 & 2,50 & 0,84 & 2,61 & 0,87 \\
\hline $\mathrm{RSC} / \mathrm{A}$ & 2,92 & 1,00 & 3,25 & 0,94 & 3,10 & 0,98 \\
\hline \multirow[t]{2}{*}{$\mathrm{RS} / \mathrm{A}$} & 3,88 & 0,82 & 3,97 & 0,82 & 3,93 & 0,81 \\
\hline & \multicolumn{2}{|c|}{$\mathrm{N}=51$} & \multicolumn{2}{|c|}{$N=64$} & \multicolumn{2}{|c|}{$\mathrm{N}=115$} \\
\hline $\begin{array}{l}\text { Sexo } \\
\text { feminino }\end{array}$ & $M$ & $D P$ & $M$ & $D P$ & $M$ & $D P$ \\
\hline DPI & 7,71 & 5,16 & 6,21 & 3,84 & 6,89 & 4,53 \\
\hline $\mathrm{RSC} / \mathrm{E}$ & 1,71 & 0,56 & 2,11 & 0,85 & 1,93 & 0,75 \\
\hline $\mathrm{RS} / \mathrm{E}$ & 2,76 & 0,76 & 2,96 & 0,92 & 2,87 & 0,86 \\
\hline $\mathrm{RSC} / \mathrm{A}$ & 2,52 & 1,18 & 2,61 & 1,00 & 2,57 & 1,08 \\
\hline \multirow[t]{2}{*}{$\mathrm{RS} / \mathrm{A}$} & 3,85 & 0,94 & 3,69 & 0,90 & 3,77 & 0,92 \\
\hline & \multicolumn{2}{|c|}{$\mathrm{N}=62$} & \multicolumn{2}{|c|}{$\mathrm{N}=75$} & \multicolumn{2}{|c|}{$\mathrm{N}=137$} \\
\hline Total & $M$ & $D P$ & $M$ & $D P$ & $M$ & $D P$ \\
\hline DPI & 9,14 & 5,76 & 8,08 & 5,31 & 8,56 & 5,53 \\
\hline $\mathrm{RSC} / \mathrm{E}$ & 2,08 & 0,87 & 2,33 & 0,94 & 2,22 & 0,91 \\
\hline $\mathrm{RS} / \mathrm{E}$ & 2,75 & 0,82 & 2,75 & 0,91 & 2,75 & 0,87 \\
\hline $\mathrm{RSC} / \mathrm{A}$ & 2,70 & 1,12 & 2,91 & 1,02 & 2,81 & 1,07 \\
\hline $\mathrm{RS} / \mathrm{A}$ & 3,87 & 0,88 & 3,82 & 0,87 & 3,84 & 0,87 \\
\hline & & & & & & \\
\hline
\end{tabular}

Nota . DPI = Índice global do duplo-padrão sexual individual; RSC/E = Relação sem comprometimento/ elevado número de parceiros sexuais; $\mathrm{RS} / \mathrm{E}=$ Relacionamento sério/elevado número de parceiros sexuais; RSC/A = Relação sem comprometimento/ausência de experiência sexual; RS/A = Relacionamento sério/ausência de experiência sexual. 


\subsection{Duplo-padrão sexual social}

$\mathrm{Na}$ análise da dimensão social do duplo-padrão sexual, é considerado o indice global do duplo-padrão sexual social, avaliado numa escala de cinco pontos, correspondendo a uma maior pontuação, uma maior concordância face ao duplo-padrão sexual social. Considerando toda a amostra $(N$ $=308$ ), a média obtida demonstra uma clara tendência no sentido da sua aceitação $(M=4.37, D P=.51)$. Para aferir o grau de adesão ao duplo-padrão social, comparámos as frequências das categorias de resposta relativas ao grau de adesão ao duplo-padrão sexual social.

\subsubsection{Religião}

No Quadro 3, apresentam-se as estatísticas descritivas ajustadas para a idade relativamente ao indice global do duplo-padrão sexual social ${ }^{19}$. Os três grupos de religião não diferem significativamente na aceitação do duplo-padrão sexual social, nem devido ao efeito isolado da religião $[F(2$, $293)=1.03, p>0,30]$, nem ao efeito de interacção entre o sexo e a religião $[F(2,293)=0,59, p>0,50]$. As diferenças entre os sexos na adesão ao duplo-padrão sexual social vão no sentido de uma maior concordância face ao duplo-padrão sexual social por parte das mulheres do que por parte dos homens $\left[F(1,293)=10.21, p<0,01, \eta^{2}=0,08\right]$.

Quadro 3: Índice global do duplo-padrão sexual social em função da religião e do sexo: Médias e desvios-padrão ajustados para a idade.

\begin{tabular}{|c|c|c|c|c|c|c|c|c|}
\hline & \multicolumn{2}{|c|}{$\begin{array}{c}\text { Católicos } \\
\text { praticantes } \\
(N=72)\end{array}$} & \multicolumn{2}{|c|}{$\begin{array}{c}\text { Católicos não } \\
\text { praticantes } \\
(N=184)\end{array}$} & \multicolumn{2}{|c|}{$\begin{array}{c}\text { Sem } \\
\text { religião } \\
(N=44)\end{array}$} & \multicolumn{2}{|c|}{$\begin{array}{c}\text { Total } \\
(N=300)\end{array}$} \\
\hline & $M$ & $D P$ & $M$ & $D P$ & $M$ & $D P$ & $M$ & $D P$ \\
\hline Sexo masculino & 4,22 & 0,10 & 4,30 & 0,05 & 4,27 & 0,11 & 4,26 & 0,52 \\
\hline Sexo feminino & 4,39 & 0,07 & 4,46 & 0,05 & 4,60 & 0,10 & 4,48 & 0,04 \\
\hline Total & 4,31 & 0,06 & 4,38 & 0,04 & 4,44 & 0,07 & & \\
\hline
\end{tabular}

19 Como o teste para a idade foi significativo $[F(1,293)=5.10, p<0,05]$, justifica-se o recurso à análise da covariância, em alternativa à simples análise da variância, para a remoção do efeito da idade dos participantes. 
A distribuição dos inquiridos consoante o seu grau adesão ao duplo-padrão sexual social e a religião consta do Quadro 4. As percentagens dos três grupos religiosos são próximas na adesão ao duplo-padrão sexual social, não existindo diferenças significativas entre eles $(p=0,55)^{20}$.

Quadro 4. Grau de adesão ao duplo padrão sexual social em função da religião: Frequências

\begin{tabular}{|c|c|c|c|c|c|c|c|c|}
\hline & \multicolumn{2}{|c|}{$\begin{array}{c}\text { Católicos } \\
\text { praticantes }\end{array}$} & \multicolumn{2}{|c|}{$\begin{array}{c}\text { Católicos não } \\
\text { praticantes }\end{array}$} & \multicolumn{2}{|c|}{$\begin{array}{c}\text { Sem } \\
\text { religião }\end{array}$} & \multicolumn{2}{|c|}{ Total } \\
\hline & $N$ & $\%$ & $N$ & $\%$ & $N$ & $\%$ & $N$ & $\%$ \\
\hline $\begin{array}{l}\text { Não adesão ao duplo- } \\
\text {-padrão sexual social }\end{array}$ & 4 & 5,6 & 14 & 7,6 & 1 & 2,3 & 19 & 6,3 \\
\hline $\begin{array}{l}\text { Adesão ao duplo- } \\
\text {-padrão sexual social } \\
\text { com discriminação das } \\
\text { mulheres }\end{array}$ & 66 & 91,7 & 164 & 89,1 & 40 & 90,9 & 270 & 90,0 \\
\hline $\begin{array}{l}\text { Adesão ao duplo- } \\
\text {-padrão sexual social } \\
\text { com discriminação dos } \\
\text { homens. }\end{array}$ & 2 & 2,8 & 6 & 3,3 & 3 & 6,8 & 11 & 3,7 \\
\hline Total & 72 & 100 & 184 & 100 & 44 & 100 & 300 & 100 \\
\hline
\end{tabular}

\subsubsection{Posição política}

A análise dos resultados da análise da covariância ${ }^{21}$, tendo como factores a posição política e o sexo e como variável dependente o índice global do duplo-padrão sexual social, permite-nos concluir que o efeito isolado da posição política não atinge o limiar de significância estatística $[F(1$, $247)=0,01, p>0,90]$, mas o efeito de interacção entre a posição política $\mathrm{e}$ o sexo é significativo $[F(1,247)=3.91, p<0,05]$. Os homens que se situam politicamente à direita, relativamente aos que se posicionam à esquerda,

20 Nesta análise utilizámos o teste exacto de Fisher, na medida em que em quatro das células da tabela $3 \times 3$ existem menos de cinco participantes, impossibilitando a interpretação do teste $\chi^{2}$ de Pearson.

21 Como o efeito da idade foi significativo $[F(1,247)=2.59, p<0,05]$, optámos por considerar as médias ajustadas para a idade e a análise da covariância. 
revelam maior concordância em relação ao facto das mulheres serem avaliadas mais negativamente do que os homens pela sociedade quanto ao seu comportamento sexual. Contudo, esta diferença surge no sentido inverso nos inquiridos do sexo feminino, ou seja, as mulheres politicamente à esquerda mostram maior aceitação relativamente ao duplo-padrão sexual social do que as mulheres politicamente à direita. Mais uma vez, as diferenças entre homens e mulheres na aceitação do duplo-padrão sexual social são significativas $\left[F(1,247)=9.06, p<0,01, \eta^{2}=0,08\right]$ e vão no sentido já referido na análise da variável religião. No Quadro 5, indicam-se as médias e os desvios-padrão ajustados para a idade.

Quadro 5. Índice global do duplo-padrão sexual social em função da posição política e do sexo: Médias e desvios-padrão ajustados para a idade.

\begin{tabular}{|c|c|c|c|c|c|c|}
\hline & \multicolumn{2}{|c|}{$\begin{array}{c}\text { Direita } \\
(N=113)\end{array}$} & \multicolumn{2}{|c|}{$\begin{array}{c}\text { Esquerda } \\
(N=139)\end{array}$} & \multicolumn{2}{|c|}{$\begin{array}{c}\text { Total } \\
(N=252)\end{array}$} \\
\hline & $M$ & $D P$ & $M$ & $D P$ & $M$ & $D P$ \\
\hline Sexo masculino & 4,33 & 0,07 & 4,20 & 0,06 & 4,27 & 0,05 \\
\hline Sexo feminino & 4,39 & 0,06 & 4,52 & 0,06 & 4,46 & 0,04 \\
\hline Total & 4,36 & 0,05 & 4,36 & 0,06 & & \\
\hline
\end{tabular}

Quadro 6. Grau de adesão ao duplo padrão sexual social em função da posição política: Frequências

\begin{tabular}{|c|c|c|c|c|c|c|}
\hline & \multicolumn{2}{|c|}{ Direita } & \multicolumn{2}{|c|}{ Esquerda } & \multicolumn{2}{|c|}{ Total } \\
\hline & $N$ & $\%$ & $N$ & $\%$ & $N$ & $\%$ \\
\hline Não adesão ao duplo-padrão sexual social & 6 & 5,3 & 8 & 5,8 & 14 & 5,5 \\
\hline $\begin{array}{l}\text { Adesão ao duplo-padrão sexual social com } \\
\text { discriminação das mulheres }\end{array}$ & 104 & 92,0 & 124 & 89,2 & 228 & 90,5 \\
\hline $\begin{array}{l}\text { Adesão ao duplo-padrão sexual social com } \\
\text { discriminação dos homens }\end{array}$ & 3 & 2,7 & 7 & 5,0 & 10 & 4,0 \\
\hline Total & 113 & 100 & 139 & 100 & 252 & 100 \\
\hline
\end{tabular}


A distribuição dos participantes de acordo com o seu grau de adesão ao duplo-padrão sexual social e a sua posição política está indicada no Quadro 6. Os jovens politicamente à direita não diferem dos jovens politicamente à esquerda no seu grau de adesão ao duplo-padrão sexual social $(p=0,72)^{22}$.

\section{Discussão}

Em geral, os resultados do estudo permitem-nos constatar que, a par de grandes mudanças sociais que traduzem uma maior igualdade entre os sexos nas oportunidades em diversos domínios, continuam a persistir representações discriminativas em relação aos comportamentos das mulheres. No domínio da sexualidade, observamos que, embora a nível comportamental, homens e mulheres tendam para um padrão singular (cf. Alves, 2004), ao nível da percepção desses mesmos comportamentos, continuam a observar-se diferenças importantes. Em particular, os resultados apontam para uma clara e generalizada tendência para a adesão ao duplo-padrão ao nível individual, embora numa forma atenuada, na avaliação dos comportamentos e atitudes sexuais das mulheres e dos homens. É, contudo, visível a maior adesão a esse duplo-padrão por parte dos jovens do sexo masculino, também encontrada por Muehlenhard e Quackenbush (1998). Em concordância com Milhausen e Herold (2001), o duplo-padrão sexual reúne maior consensualidade na sua forma social, isto é, enquanto dualidade na percepção do que é a avaliação dos comportamentos sexuais por parte da sociedade em geral, que, embora tenha reunido a aceitação de cerca de $90.0 \%$ dos jovens, é ainda mais dominante entre as raparigas, que constituem os alvos de discriminação do duplo-padrão sexual individual.

O duplo-padrão sexual, quando conceptualizado a um nível social, poderá ser visto como expressão dos estereótipos sexuais no domínio da sexualidade pré-matrimonial, enquanto representações sociais ao nível ideológico (Doise, 1984), que dominam, não só as atitudes, mas principalmente os discursos dos jovens (cf. Baptista, 1999; Vilar \& Gaspar, 1999). A rigidez dos preconceitos que imprimem diferentes significados às práticas sexuais masculinas e femininas, assim como a sua perpetuação geração após geração, leva a que a sociedade continue a ser percepcionada como julgando diferenciadamente os homens e as mulheres. Este duplo-padrão sexual social surge nesta amostra de jovens universitários como uma representação

22 Nesta análise utilizámos o teste exacto de Fisher, na medida em que numa das células da tabela $2 \times 3$ existem menos de cinco participantes, não permitindo a interpretação do teste $\chi^{2}$ de Pearson. 
social hegemónica (Moscovici, 1988), comum aos grupos religiosos e de posição política considerados. Estamos, então, face a uma aparente igualdade numa desigualdade socialmente reconhecida de modo generalizado pelos próprios indivíduos, traduzida pela ideia «eu não discrimino, mas penso que a sociedade em geral o faz». Esta desigualdade de género apoia-se na forma dualista de pensar a sexualidade, cujos significados diferenciam os sexos. Em particular, as concepções da sexualidade traduzem ainda, de forma geral, um duplo-padrão sexual e moral que discrimina as mulheres, cujos comportamentos e atitudes são avaliados como desviantes à «normalidade», mas que, quando adoptados pelos homens, correspondem à própria «normalidade». Estas normas, que definem o que é ou não social e moralmente aceitável nos comportamentos femininos, têm origens remotas na história, tendo resultado de um processo de construção social, baseado em pressupostos essencialistas, teorias e mitos, que alimentam crenças, formam atitudes e orientam comportamentos.

Os resultados da análise da influência da opção religiosa e da posição política, enquanto sistemas ideológicos, sobre as representações sociais da sexualidade pré-matrimonial, são, em geral e tendencialmente, concordantes com os de outros estudos nacionais (e.g., Alferes, 1997; França, 1986, Pais, 1985; Vasconcelos, 1998): os factores religiosidade e conservadorismo político estão negativamente associados à permissividade das atitudes sexuais. Em termos atitudinais, volta a verificar-se uma clivagem entre os católicos praticantes, por um lado, e os católicos não praticantes e os ateus, por outro, na medida em que o primeiro grupo mostra menor aceitação face à possibilidade de um relacionamento sem comprometimento com alguém que já teve um elevado número de parceiros sexuais. Na adesão ao duplo-padrão sexual, quer individual, quer social, não se observaram diferenças explicadas pela religiosidade dos jovens. Em síntese, da revisão de estudos anteriores e dos resultados desta investigação sobressaem dois aspectos principais. Em primeiro lugar, a clivagem entre os jovens católicos praticantes e os jovens católicos não praticantes ou sem religião e o maior conservadorismo dos primeiros ao nível dos comportamentos e da normatividade comportamental. Em segundo lugar, a tendência comum e praticamente indiferenciada dos três grupos para a adesão ao duplo-padrão sexual, nas suas duas formas, individual e social.

No que diz respeito à posição política, os jovens de esquerda, independentemente do sexo, mostram um maior grau de aceitação face ao relacionamento ocasional com um parceiro com muita experiência sexual comparativamente aos jovens de direita. No entanto, verificámos algumas interacções da posição política com a variável sexo, que embora não tenham sido previstas, poderão futuramente levantar algumas questões quanto à especificidade da influência da ideologia política nas atitudes sexuais dos 
homens e das mulheres. $\mathrm{O}$ que nos interessou realçar aqui, não foi o estudo das ideologias consensuais em si mesmo, mas a forma como conduzem à formação de representações sociais, direccionam e organizam as atitudes e os comportamentos dos indivíduos de grupos específicos. Concretamente, a posição política de esquerda distancia os sexos em relação a algumas atitudes. As mulheres de esquerda, em oposição aos homens de esquerda, revelam ser o grupo mais permissivo em relação à possibilidade de um envolvimento sexual ocasional com alguém com um elevado número anterior de parceiros sexuais. Em contraste, os jovens de direita adoptam atitudes mais moderadas e menos diferenciadoras em função do sexo.

As concepções dos jovens acerca da vida política vêm a revelar-se menos ideológicas e mais instrumentais que em gerações anteriores (Reis, 1985), passando-se o mesmo em relação à religião. Podemos afirmar, então, que o duplo-padrão sexual foi ganhando uma autonomia e sustentabilidade como representação social, que embora tenha sido alimentada ao longo do tempo pela doutrina da religião católica e pela repressão político-legal, tende a persistir para além das posições religiosas e políticas dos jovens.

Uma das limitações deste estudo prende-se com as características dos jovens da amostra recolhida, por serem todos eles universitários, não estando contemplada a variabilidade sócio-cultural que uma abordagem psicossociológica deve considerar. Assim, um estudo acerca do duplo-padrão sexual com participantes de outros níveis culturais e sociais, tal como com diferentes nacionalidades, poderá trazer importantes contributos para a compreensibilidade das diferenças associadas aos significados de género na sexualidade no modelo das representações sociais. Outra importante contribuição passaria pelo investimento em estudos longitudinais ou transversais com várias categorias etárias, que melhor dariam conta da mudança ou da estabilidade dos comportamentos e normas associados à sexualidade pré-matrimonial (James, 1997).

\section{Referências}

Alferes, V. (1987). O corpo: Regularidades discursivas, representações e patologias. Revista Crítica de Ciências Sociais, 23, 211-219.

Alferes, V. (1997). Encenações e comportamentos sexuais: Para uma psicologia social da sexualidade. Porto: Afrontamento.

Alves, M. P. (2004). Género e sexualidade: O duplo-padrão sexual como representação social. Dissertação de Mestrado não publicada. Instituto Superior de Ciências do Trabalho e da Empresa, Lisboa.

Amâncio, L. (1998a). Masculino e feminino: A construção social da diferença (2a ed.). Porto: Afrontamento. 
Amâncio, L. (1998b). Género e ciência no percurso da psicologia social. In M. B. Silva \& A. Cova (Eds.), Estudos sobre as mulheres (pp. 9-16). Lisboa: Universidade Aberta.

Amâncio, L. (2001). O género na psicologia: Uma história de desencontros e rupturas. Psicologia, 15(1), 9-26.

Antunes, M. L. (1985). Representações sociais dos jovens e religião. Análise Social, $21(86), 283-311$.

Apostolidis, T. (1995). Lés représentations sociales de la sexualité et les comportements face au sida dans une population de jeunes adultes, une comparaison France/Grèce. In N. Bajos, M. Bozon, A. Giami, V. Doré \& Y. Souteyrand (Eds.), Sexualité et sida: Recherches en sciences sociales (pp. 247-250). Paris: ANRS.

Baptista, M. C.(1999). O discurso de adolescentes do sexo masculino sobre sexualidade e saúde reprodutiva. Tese de Licenciatura. Manuscrito não publicado, Instituto Superior do Trabalho e da Empresa, Lisboa.

Deaux, K., \& Kite, M. (1989). Thinking about gender. In B. B. Hess \& M. M. Ferree (Eds.), Analysing gender: A handbook of social science research (pp. 92-117). Newbury Park, CA: Sage Publications.

DeLamater, J. D. (1987). A sociological approach. In J. H. Geer \& W. T. O'Donohue (Eds.), Theories of human sexuality (pp. 237-255). New York: Plenum Press.

Doise, W. (1984). Social representations, inter-group experiments and levels of analysis. In R. M. Farr \& S. Moscovici (Eds.), Social representations (pp. 255 -268). Cambridge: Cambridge University Press.

Doise, W. (1990). Les représentations sociales. In R. Ghiglione, C. Bonnet \& J.-F. Richard (Eds.), Traité de psychologie cognitive: Vol 3. Cognition, représentation, communication (pp. 111-174). Paris: Dunod.

França, L. (1986). A religião, na memória e na actualidade dos jovens portugueses. Desenvolvimento, Número Especial, 29-46.

Giami, A. (1999). Représentations et sexualité: Psychologie sociale et pluridisciplinarité. In M. A. Loyola (Ed.), La sexualité dans les sciences humaines (pp. 215-241). Paris: L'Harmatton.

James, J. (1997). What are social the issues involved in focusing on difference in the study of gender?. Journal of Social Issues, 2(53), 213-232.

Jodelet, D. (1997). Représentations sociales, un domaine en expansion. In D. Jodelet (Ed.), Les représentations sociales $\left(5^{\mathrm{e}}\right.$ ed.) (pp. 47-78). Paris: PUF [ $1^{\mathrm{re}}$ éd.: 1989].

Jovchelovitch, S. (1994). Vivendo a vida com os outros: Intersubjectividade, espaço público e representações sociais. In P. Guareschi \& S. Jovchelovitch (Eds.), Textos em representações sociais (4 ${ }^{\mathrm{a}}$ ed.) (pp. 63-85). Petrópolis: Editora Vozes.

Miguel, N., \& Vilar, D. (1986). Afectividade e sexualidade no novo contexto social e cultural. Desenvolvimento, Número Especial, 103-126.

Milhausen, R. R., \& Herold, E. S. (2001). Reconceptualizing the sexual double standard. Journal of Psychology and Human Sexuality, 2(13), 63-83. 
Moscovici, S. (1984). The phenomenon of social representations. In R. M. Farr \& S. Moscovici (Eds.), Social representations (pp. 3-69). Cambridge: Cambridge University Press.

Moscovici, S. (1988). Notes towards of social representations. European Journal of Social Psychology, 18, 211-250.

Muehlenhard, C. L., \& Quackenbush, D. M. (1998). Sexual double standard scale. In C. M. Davis, W. L. Yarber, R. Bauserman, G. Schreer \& S. L. Davis (Eds.), Handbook of sexuality related measures (pp. 186-188). Thousand Oaks, CA: Sage Publications.

Paicheler, G. (1995). Normes et representations comme determinants sociaux de la sexualité. In N. Bajos, M. Bozon, A. Giami, V. Doré \& Y. Souteyrand (Eds.), Sexualité et sida: Recherches en sciences sociales (pp. 99-116). Paris: ANRS.

Pais, J. M. (1985). Família, sexualidade e religião. Análise Social, 21(86), 345-389

Palmonari, A., \& Doise, W. (1986). Caractéristiques des representations sociales. In W. Doise \& A. Palmonari, L'étude des représentations sociales. Neuchâtel: Delachaux \& Niestlé.

Reis, M. L. (1985). Inter-relação entre as posições religiosas e a participação social dos jovens: respostas a um inquérito. Análise Social, $21(86), 313-344$.

Reis, M. L. (1986). Tendências recentes da atitude dos jovens portugueses face à política: Análise comparativa com os indicadores europeus. Desenvolvimento, Número Especial, 67-78.

Reiss, I. L. (1960). Premarital sexual standards in America. New YorK: Free Press.

Reiss, I. L. (1967). The social context of premarital sexual permissiveness. New York: Holt, Rinehart and Winston.

Sá, C. P. (1998). A construção do objecto de pesquisa em representações sociais. Rio de Janeiro: Edições UERJ.

Sheeran, P., Spears, R., Abraham, S., \& Abrams, D. (1996). Religiosity, gender, and the double standard. The Journal of Psychology, 130(1), 23-32.

Spink, M. J. (1994). Desvendando as teorias implícitas: Uma metodologia de análise das representações sociais. In P. Guareschi \& S. Jovchelovitch (Eds.), Textos em representações sociais ( $4^{\mathrm{a}}$ ed.) (pp. 117-145). Petrópolis: Editora Vozes.

Vala, J. (2000). Representações sociais e psicologia social do conhecimento quotidiano. In J. Vala \& M. B. Monteiro (Eds.), Psicologia social ( $3^{\mathrm{a}}$ ed.) (pp. $457-$ -502). Lisboa: Fundação Calouste Gulbenkian.

Vasconcelos, P. (1998). Práticas e discursos da conjugalidade e de sexualidade dos jovens portugueses. In M. V. Cabral \& J. M. Pais (Eds.), Jovens portugueses de hoje: Resultados do inquérito de 1997 (pp. 215-305). Oeiras: Celta Editora.

Vilar, D. (2003). Falar disso: A educação sexual nas famílias dos adolescentes. Porto: Edições Afrontamento.

Vilar, D., \& Gaspar, A. M. (1999). Traços redondos: A gravidez em mães solteiras. In J. M. Pais, Traços e riscos de vida: Uma abordagem qualitativa a modos de vida juvenil (pp. 31-91). Porto: Ambar.

Weinberg, M. S., Lottes, I., \& Shaver, F. M. (2000). Sociocultural correlates of permissive sexual attitudes: A test of Reiss hypotheses about Sweden and the United States. The Journal of Sex Research, 37(1), 44-52. 